\title{
Production and characterization of monoclonal antibodies against Encephalitozoon intestinalis and Encephalitozoon sp. spores and their developmental stages
}

Fernando Izquierdo ${ }^{1,2^{*}}$, Hercules Moura ${ }^{2}$, Fernando Jorge Bornay-Llinares ${ }^{3}$, Rama Sriram²^, Carolina Hurtado ${ }^{1}$, Ángela Magnet', Soledad Fenoy ${ }^{1}$, Govinda Visvesvara $^{2}$ and Carmen del Aguila'

\begin{abstract}
Background: Microsporidia are intracellular obligate parasites traditionally associated with immunosuppressed patients; their detection in immunocompetent patients has increased, highlighting their possible importance as emerging pathogens. Detection of spores in stools, urine, body fluids and tissues is difficult and immunological techniques such as immunofluorescence have proved to be a useful and reliable tool in the diagnosis of human microsporidiosis. For this reason, we have produced and characterized monoclonal antibodies (MAbs) specific for Encephalitozoon intestinalis (the second most frequent microsporidian infecting humans), and other Encephalitozoon species, that can be used in different diagnostic techniques.

Results: Seven MAbs were selected in accordance with their optical density (OD). Four (4C4, 2C2, $2 \mathrm{E} 5$ and 2H2) were isotype IgG2a; two (3A5 and 3C9) isotype IgG3, and one Mab, 1D7, IgM isotype. The selected monoclonal antibody-secreting hybridomas were characterized by indirect immunofluorescence antibody test (IFAT), enzymelinked immunosorbent assay (ELISA), Western blot, immunoelectron microscopy (Immunogold) and in vitro cultures. The study by IFAT showed different behavior depending on the MAbs studied. The MAbs 4C4, 2C2, $2 \mathrm{E} 5$ and $2 \mathrm{H} 2$ showed reactivity against epitopes in the wall of the spore (exospore and endospore) epitopes located in Encephalitozoon sp. spores, whereas the MAbs 3A5, 1D7 and 3C9 showed reactivity against internal epitopes (cytoplasmic contents or sporoplasm) of E. intestinalis spores. All MAbs recognized the developing parasites in the in vitro cultures of E. intestinalis. Additionally, 59 formalin-fixed stool samples that had been previously analyzed were screened, with 26 (44\%) presenting microsporidian spores (18 samples with E. intestinalis and 8 samples with Enterocytozoon bieneusi). Detection of microsporidian spores by microscopy was performed using Calcofluor stain, Modified Trichrome, Quick-Hot Gram Chromotrope, as well as IFAT using MAbs 4C4, 2C2, 2E5 and $2 \mathrm{H} 2$. The 4 MAbs tested clearly recognized the larger spores corresponding to $E$. intestinalis, but showed no reactivity with Enterocytozoon bieneusi spores. The mass spectrometry and proteomic study revealed that the Mabs 4C4, 2C2, $2 \mathrm{E} 5$ and $2 \mathrm{H} 2$ recognized the Spore Wall Protein 1 (SWP1) as the antigenic target.

\footnotetext{
* Correspondence: ferizqui@ceu.es

'Deceased

'Laboratorio de Parasitología, Universidad San Pablo CEU, Madrid, Spain

${ }^{2}$ Centers for Disease Control and Prevention, Atlanta, GA, USA

Full list of author information is available at the end of the article
} 
(Continued from previous page)

Conclusions: The IFAT-positive MAbs exhibited excellent reactivity against spores and developmental stages, permitting their use in human and animal diagnosis. The epitopes recognized (exospore, endospore and cytoplasmic contents) by the different MAbs developed need further study, and may reveal potential targets for vaccine development, immunotherapy and chemotherapy.

Keywords: Encephalitozoon intestinalis, Encephalitozoon sp., Monoclonal antibodies, Spores, Developmental stages, Diagnosis

\section{Background}

Microsporidia are intracellular obligate parasites, ubiquitous in nature that can infect all animal phyla $[1,2]$. Considered as human opportunistic pathogens, microsporidiosis is traditionally associated with immunosuppressed patients, such as those that are HIV-positive [3]. Nonetheless, their detection in immunocompetent patients has increased, highlighting their possible importance as emerging pathogens. However, the real prevalence of human infection has been underestimated $[2,4,5]$, due to the difficulty of their diagnosis.

Detection of spores in stools, urine, body fluids and tissues is difficult, although the development of reliable differential staining techniques, such as Weber's chromotrope-based stain and its modifications $[6,7]$, has improved the diagnosis of microsporidia. Nonetheless, these techniques are time consuming and intensive training is necessary to use them reliably. Moreover, diagnosis may be missed if the parasite burden is low or misdiagnosis can occur due to the presence of small yeast and/or sporulated bacteria in the samples that also stain. Morphological characteristics of the spores are ineffective in the identification of species, essential when choosing an appropriate treatment [8]. On the other hand, microsporidial DNA detection using molecular methods (mainly PCR) appears to be the most sensitive and specific method for species identification, but is expensive and not affordable in many clinical diagnostic laboratories. Furthermore, the presence of inhibitors of the polymerase enzyme in clinical samples (mainly stools), discourage their use [9-12].

In previous years, various studies have described the production and characterization of policlonal and monoclonal antibodies that recognize genus- and/or speciesspecific antigens of different microsporidia. Immunological techniques such as immunofluorescence has proved to be a useful and reliable tool in the diagnosis of human microsporidiosis [5, 12-27].

For this reason we have produced and characterized monoclonal antibodies (MAbs) specific for Encephalitozoon intestinalis (the second most frequent microsporidian infecting humans) and other Encephalitozoon species (E. cuniculi and E. hellem) that can be used in different diagnostic techniques.

\section{Methods \\ Biological samples \\ Microsporidian spores}

Encephalitozoon intestinalis (CDC:V297, provided by Dr Govinda Visvesvara, CDC, USA) [28], Encephalitozoon cuniculi (USP-A1, provided by Dr Carmen del Águila, USP-CEU, Spain) [29] and Encephalitozoon hellem (PV5-95, provided by $\mathrm{Dr}$ Massimo Scaglia) [30] were cultured in Vero-E6 cells (provided by Dr Govinda Visvesvara, CDC, USA), harvested weekly, pooled, purified separately and stored at $4{ }^{\circ} \mathrm{C}$ until use, according to the method previously described by Visvesvara et al. [31]. Enterocytozoon bieneusi spores were obtained from an HIV-infected patient fecal sample provided by Dr Carmen del Águila (USP-CEU, Spain).

\section{Microsporidian soluble antigen}

Glass beads were used for disruption of the purified Encephalitozoon isolates in $2.5 \% \mathrm{SDS} / 10 \%$ 2-ME, using FP120 FastPrep ${ }^{\text {Tw }}$ Cell Disruptor (Bio 101, Cedex, France) and the protein content was determined by the Bradford method as described previously [32].

\section{Enteropathogenic bacteria and other intestinal parasites}

MAbs were assessed for cross-reactivity to enteropathogenic bacteria (Proteus vulgaris, Pseudomonas aeruginosa, Escherichia coli, Shigella dysenteriae, Salmonella typhi, Yersinia enterocolitica, Enterococcus faecalis, Vibrio cholera, Klebsiella pneumonia and Enterobacter aerogenes) provided by the Hospital Instituto de Salud Carlos III and the Microbiology Laboratory USP-CEU (Madrid, Spain), and the intestinal parasites (Giardia sp., Entamoeba histolytica, Entamoeba coli, Cryptosporidium sp., Cyclospora sp., Isospora sp. and Blastocystis sp.) provided by the Hospital Gregorio Marañon and Instituto de Salud Carlos III (Madrid, Spain).

\section{Human fecal samples and ethics statement}

Twenty-six human fecal samples obtained from HIVpositive and microsporidia-positive patients from Atlanta (CDC, Georgia, USA) were selected for this study. These samples had previously been identified by staining and molecular sequencing as $E$. intestinalis-positive (18 samples) and as E. bieneusi-positive (8 samples) [23]. These 
samples were stored at $4{ }^{\circ} \mathrm{C}$ and preserved in formalin. Use of trade names is for identification only and does not imply endorsement by the Centers for Disease Control and Prevention/ the Public Health Service, or the U.S. Department of Health and Human Services.

\section{Animals and immunization protocol}

Hybridoma development and MAbs production was performed in adult (7-week-old) female BALB/c mice purchased from Charles Rives Laboratories. All mice were housed in filter-topped plastic cages with wood chip bedding and maintained at $12 \mathrm{~h}$ photoperiod cycles. Food and water were provided ad libitum.

Three immunization protocols were performed using three groups of six mice in each. All animals were immunized intraperitoneally (i.p.) with $E$. intestinalis $\left(5 \times 10^{7}\right.$ spores per $\left.200 \mu \mathrm{l}\right)$. In protocols (immunizations) 1 and 2, non-purified and purified spores of $E$. intestinalis, respectively, were used in five inoculations (days $0,7,21,35$ and 42). In the third protocol (immunization), purified spores of $E$. intestinalis were emulsified at a 1:1 ratio in Freund's adjuvant (Sigma-Aldrich Laboratories, Saint Louis, MO, USA) in four inoculations (days 0, 21, 42 and 56). For the first inoculation, Freund's complete adjuvant was used; Freund's incomplete adjuvant was used for subsequent inoculations.

In order to determine which immunization protocol produced the highest parasite specific antibody responses, mice sera were screened by indirect immunofluorescence antibody (IFAT). Sera were stored at $-80{ }^{\circ} \mathrm{C}$ and used as positive controls.

\section{Production of MAbs}

The MAbs were produced using the Köhler and Milstein method with modifications [33]. Three or four days before cell fusion, selected mice were boosted intravenously by an antigen inoculum $\left(5 \times 10^{7}\right.$ spores in 50 to $100 \mu \mathrm{l}$ of sterile saline solution). The spleen cells from the donor mouse were collected and fused with a nonsecreting murine myeloma cell line, P3X63-Ag8.653 (BALB/c MOP21. ATCC\#CRL-1580 ${ }^{\text {ms }}$ ) at a 5:1 ratio, using 50\% polyethylene glycol (PEG). The cells were distributed into 96-well tissue culture plates with a feeder layer, at a concentration of $1-3 \times 10^{6}$ cells $/ \mathrm{ml}$ (100 $\mu \mathrm{l} /$ well). The hybridomas were selected by growth in a selective medium (RPMI-1640, 18\% fetal bovine serum and $2 \mathrm{mM}$ L-glutamine with hypoxanthineaminopterin-thymidin (HAT) without antibiotics), and placed at $37{ }^{\circ} \mathrm{C}$ in $5 \% \mathrm{CO}_{2}$. After 15 days, the undiluted culture supernatants were screened for the presence of anti-E. intestinalis antibodies by ELISA and IFAT. Hybridoma supernatants that showed antibody activity against $E$. intestinalis were expanded on to 24-well plates and cloned twice by limiting dilution.
Enzyme-linked immunosorbent assay (ELISA)

ELISA 96 microtitter plates (Nunc-Immuno Plate PolySorp $^{\mathrm{Tm}}$, Darmstadt, Germany) were coated with E. intestinalis soluble antigen $(0.8 \mu \mathrm{g} / \mathrm{ml})$ as described previously [4]. Hybridomas with an optical density (OD) greater or equal to 0.5 were selected following the criteria of Pomport-Castillon et al. [34].

\section{Immunofluorescence antibody test (IFAT) Hybridoma screening}

E. intestinalis purified spores were used to screen hybridoma supernatans and to determine the specificities of MAbs. The procedure was performed as described previously [28].

\section{Development of E. intestinalis in cell culture and immunolabeling of different stages}

Vero-E6 cells were cultivated in culture chambers with 2 wells (4.2 area $\mathrm{cm}^{2} /$ well, Ref. 155,380 , Lab-Tek ${ }^{\circledR}$ ) and infected with purified spores $\left(2 \times 10^{5}\right.$ spores $\left./ \mathrm{ml}\right)$. The developmental stages were monitored by double labeling using fluorescein and rhodamine at 24,48 and $72 \mathrm{~h}$ post-infection. A hyperimmune polyclonal rabbit sera [32] that recognizes all development stages of E. intestinalis was labeled with fluorescein and the MAbs (undiluted) labeled with rhodamine were used in order to determine the epitopes recognized by the MAb.

\section{Cross-reactivity studies}

MAbs were also assessed by IFAT for their crossreactivity to other microsporidia (E. cuniculi, E. hellem and $E$. bieneusi), enteropathogenic bacteria, and other intestinal parasites as described previously.

\section{Diagnosis of microsporidiosis in human fecal samples}

Thin smears were prepared from each of the unconcentrated human fecal samples and tested for the presence of microsporidian spores by Calcofluor (CF) [17], Modified Trichrome stain (MT) [6] and Gram-chromotrope stain (GC) [35]. IFAT with MAbs (4C4, 2C2, 2E5 and $2 \mathrm{H} 2$ ) was performed on the fecal samples using fluorescein Isothiocyanate-conjugated anti-mouse (Sigma Cat. F-1010, Saint Louis, MO, USA). Finally, Calcofluor and IFAT were performed on the same samples to compare the sensitivity and specificity between these fluorescent techniques.

\section{Isotyping}

MAb isotype and light chain composition were determined by isotyping kit Dipstick Format according to the manufacturer's instructions (Gibco-ThermoFisher, Waltham, MA, USA). 


\section{Western blot}

SDS-polyacrylamide gel electrophoresis (SDS-PAGE) was used to determine soluble protein antigen profiles of E. intestinalis, E. cuniculi and E. hellem [29].

\section{Immunoelectron microscopy}

Encephalitozoon intestinalis spores were fixed with 2\% paraformaldehyde/ $0.2 \%$ glutaraldehyde in $0.1 \mathrm{M}$ cacodylate buffer ( $\mathrm{pH}$ 7.4). After $1 \mathrm{~h}$ the spore suspension was centrifuged at $2100 \times g$ for $30 \mathrm{~min}$ and the pellet washed in $0.1 \mathrm{M} \mathrm{Na-cacodylate} \mathrm{buffer}$ and $4.5 \%$ sacarose. After dehydration with ethanol, the material was embedded in Lowicryl K4 M resin. The sections were collected on nickel grids. Spore sections were blocked with $1 \%$ BSA in TBS for $1 \mathrm{~h}$ at $37^{\circ} \mathrm{C}$ and later incubated for $1 \mathrm{~h}$ with the monoclonal antibody (1:1, 1:2, 1:5 and 1:10 dilutions of each). After intensive washings in BSA (0.1\%)-TBS (Tris-buffered saline, $\mathrm{pH} 7.4$ ), sections were incubated for $1 \mathrm{~h}$ at $37{ }^{\circ} \mathrm{C}$ with goat anti-mouse IgG/IgM labelled with 5 and $10 \mathrm{~nm}$ gold particles (Auroprobe GAM, Amersham). Controls consisted of sections incubated with the secondary antibody alone. After washing, the grids were stained with $1 \%$ uranyl acetate for $10 \mathrm{~min}$ before examination in a transmission electron microscope.

\section{Mass spectrometry and proteins}

Proteomic methods were used to determine the possible epitopes recognized by the four IFAT-positive MAbs (4C4, 2C2, 2H2 and 2E5). For this study, the species selected was E. cuniculi (USP-A1) due to the good profiles and protein fractions recognized by all MAbs using Western blot. One set of gels was transferred to blot membranes in order to determine the immunoreactivity profiles of the MAbs (dilution 1:20, iBlot ${ }^{\mathrm{TM}}$ Dry Blotting System, Invitrogen ${ }^{\mathrm{TM}}$ Carlsbard, CA, USA). This assay permits the identification of the separated proteins recognized by the MAbs. SDS-PAGE analysis (GeLCMS) and in-gel digestion were performed as described previously [36]. Briefly, NuPage ${ }^{\oplus}$ Novex $^{\oplus} 4-12 \%$ Bis-Tris Mini Gels (Invitrogen ${ }^{\mathrm{Tm}}$, Carlsbard, CA, USA) were used to determine soluble protein profiles of E. cuniculi stained with Coomasie Blue. Each gel lane was cut into 20 slices, dehydrated and digested with sequencing grade modified trypsin (Promega ${ }^{\mathrm{Tm}}$, Madison, WI, USA) and then incubated for $16 \mathrm{~h}$ at $37{ }^{\circ} \mathrm{C}$. The digests were quenched with $0.2 \%$ formic acid, sonicated and centrifuged. The supernatants were used for nanoscale high-pressure liquid chromatography (nHPLC-MS/MS) analysis.

Tryptic digests were analyzed by MS. nLCMS/MS was carried out using a nanoAcquity UPLC coupled to a QTOF Premier MS system (Waters Corporation, Milford, MA, USA). nLC separation was performed using a Symmetry C18 trapping column and a BEH C18 column
(100 $\mu \mathrm{m}$ ID $\times 100 \mathrm{~mm}$ long with $1.7 \mu \mathrm{m}$ packing), at a flow rate of $1.2 \mu \mathrm{l} / \mathrm{min}$, at $35{ }^{\circ} \mathrm{C}$. Standard water/ACN gradients containing $0.1 \%$ formic acid in both solvents were used for elution, with the ACN increasing linearly from $1 \%$ to $50 \%$ in $50 \mathrm{~min}$, and an overall cycle time of 90 min. The QTOF used an $\mathrm{MS}^{\mathrm{E}}$ (or Protein Expression) method, which involved acquiring data-independent alternating low- and high-energy (4 and 15-45 eV collision energy, respectively) scans over the $\mathrm{m} / \mathrm{z}$ range 50 1990 in $0.6 \mathrm{~s}$, along with lock mass data on a separate channel. The lock mass consisted of $100 \mathrm{fmol} / \mu^{1}$ of [Glu1]-fibrinopeptide $B$ and was delivered from the auxiliary pump with a constant flow rate of $300 \mathrm{nl} / \mathrm{min}$. Quality control of the nLC-MS/MS runs was assured by adding to each queue a protein standard consisting of a tryptic digest of yeast ADH (Waters Corporation, Milford, MA, USA) before the first sample injection and again following the last sample injection. Each digest was analyzed in triplicate (three technical replicates per sample) and their respective raw data file obtained using the $\mathrm{MS}^{\mathrm{E}}$ data-independent method was further processed using the PROTEINLYNX GLOBAL SERVER v2.4 software (PLGS, Waters Corporation), for protein identification and quantification. Database searches were performed using the PLGS Identity ${ }^{\mathrm{E}}$ database search algorithm against a UniProt protein database and provided statistically validated peptide and protein identification along with relative and absolute protein quantification analysis. Protein identifications were based on the detection of a minimum of two peptides identified per protein and a minimum of seven total product ion matches per protein. The maximum false-positive rate against the randomized forward database was set to $1 \%$.

All protein identifications were manually verified. The relative protein quantification was obtained using both the PLGS Identity ${ }^{\mathrm{E}}$ and the Expression software in the samples spiked with a known amount of standard ADH digest (100 fmol on column). The clustered data set was exported from PLGS and further evaluated with Excel (Microsoft Corporation, Redmond, WA, USA). SCAFFOLD (v3.01, Proteome Software Inc., Portland, OR, USA) was used to further validate MS/MS-based peptide and protein identifications. Peptide identifications were accepted if they could be established at $>95.0 \%$ probability as specified by the Peptide Prophet algorithm. Protein identifications were accepted if they could be established at $>99.0 \%$ probability and contained at least two identified peptides.

\section{Results}

Production of MAbs

After nine fusions of $E$. intestinalis-immunized murine spleen cells with P3X63-Ag8.653 myeloma cells, seven antibody-secreting hybridomas showed reactivity against 
E. intestinalis were selected (Table 1). ELISA screened and selected the positive hybridomas by the optical density values obtained (OD) (Table 1). The studies by IFAT revealed that four of the seven MAbs $(4 \mathrm{C} 4,2 \mathrm{C} 2,2 \mathrm{E} 5$ and 2H2) exhibited reactivity against the exospores of Encephalitozoon intestinalis, E. cuniculi and E. hellem (Table 1).

\section{Characterization of monoclonal antibodies \\ Isotyping}

The isotyping of antibodies showed that four were IgG2a (4C4, 2C2, 2E5 and 2H2), two IgG3 (3A5 and 3C9) and one IgM (1D7) (Table 1).

\section{Western blot}

The study by Western blot using E. intestinalis soluble antigen determined four different patterns (Fig. 1), bands from 36.4 to $201 \mathrm{KDa}$ (MAbs 4C4, 2C2 and 2H2) (Table 1, Fig. 1), 36.4 to $48.3 \mathrm{KDa}$ (MAb 2E5) (Table 1, Fig. 1), all showing a well-defined band at $45 \mathrm{KDa}$. The third pattern showed a band of $16 \mathrm{KDa}$ (MAb 3A5) (Table 1, Fig. 1) and the fourth, two bands around 16 and $40 \mathrm{KDa}$ (MAbs 1D7 and 3C9) (Table 1, Fig. 1). With respect to E. cuniculi and E. hellem the MAbs 4C4, 2C2, 2H2 and 2E5 showed cross-reactions with bands from 36.8 to 205 $\mathrm{KDa}$ and two well-defined bands (63 and 59.2 KDa). Finally, MAbs 1D7, 3C9 and 3A5 showed an absence of reactivity to E. cuniculi and E. hellem (Table 1).

\section{Cross-reactivity studies}

The presence of possible cross-reactions with other microsporidia (E. cuniculi, E. hellem and Enterocytozoon bieneusi), and other enteric parasites and enteric bacteria were studied. None of the IFAT-positive MAbs exhibited crossreaction with the enteric parasites and enteric bacteria

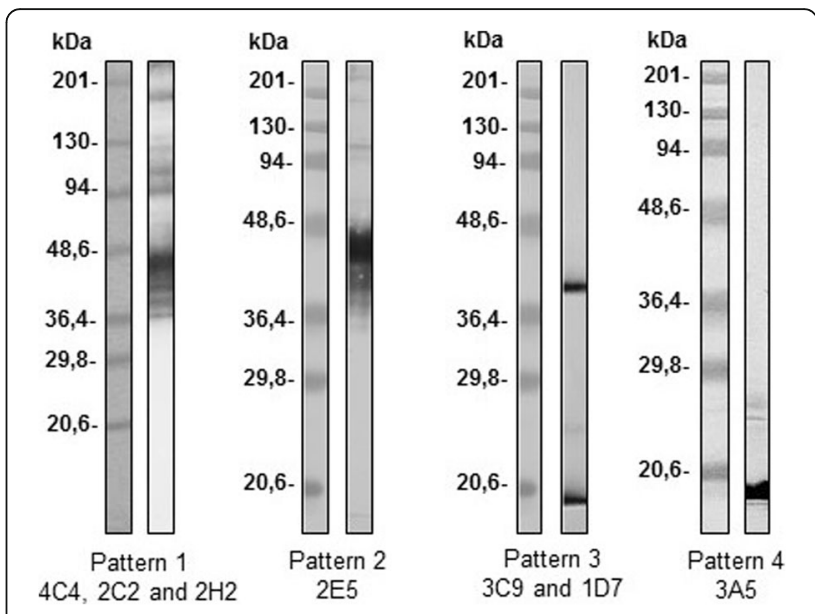

Fig. 1 Western blot of SDS-PAGE (12\%) separated proteins of $E$. intestinalis. Undiluted monoclonal antibodies: Pattern 1 (MAbs 4C4, 2C2 and 2H2); Pattern 2 (MAb 2E5); Pattern 3 (MAbs 3C9 and 1D7); Pattern 4 (MAb 3A5)

studied. However, in the case of microsporidia, the four MAbs showed cross-reactions with $E$. cuniculi and $E$. hellem by IFAT and by Western blot. MAb 2E5 could be useful in the detection of $E$. intestinalis according to the dilution used (Table 1), due to the absence of crossreactions and the four MAbs for Encephalitozoon spp. detection (undiluted saturated supernatant). In the case of E. bieneusi, no cross-reactions were detected.

\section{Immunoelectron microscopy}

The immunochemical characterization by electron microscopy (Immunogold) techniques showed that 3A5, 1D7 and 3C9 MAbs recognized internal epitopes of E. intestinalis spores (cytoplasmic contents) (Fig. 2b,

Table 1 Reactivity and characterization of MAbs to E. intestinalis

\begin{tabular}{|c|c|c|c|c|c|c|c|c|c|}
\hline \multirow[t]{2}{*}{ MAb } & \multirow{2}{*}{$\begin{array}{l}\text { Immunization } \\
\text { protocol }\end{array}$} & \multirow[t]{2}{*}{ Isotype } & \multirow{2}{*}{$\begin{array}{l}\text { ELISA } \\
\text { (OD) }\end{array}$} & \multirow[t]{2}{*}{$\mathrm{IFAT}^{\mathrm{a}}$} & \multicolumn{2}{|l|}{ WB $(K D a)^{b}$} & \multirow[t]{2}{*}{ EM } & \multicolumn{2}{|c|}{ Specificity of the MAbs (use dilution by IFAT) } \\
\hline & & & & & E. intestinalis & E. cuniculi / E. hellem & & Genus & E. intestinalis \\
\hline $4 C 4$ & 1 & $\lg _{2 a}$ & $+(1.482)$ & + & $201-36.4(45)^{c}$ & $\begin{array}{l}205-36.8 \\
(63 \& 59.2)^{c}\end{array}$ & EXP/ENP & $1: 25-1: 50$ & $1: 400^{d}$ \\
\hline $2 \mathrm{C} 2$ & 3 & $\lg G_{2 a}$ & $+(0.940)$ & + & $201-36.4(45)^{c}$ & $\begin{array}{l}205-36.8 \\
(63 \& 59.2)^{c}\end{array}$ & EXP/ENP & Not diluted & $\geq 1: 50^{d}$ \\
\hline $2 \mathrm{H} 2$ & 3 & $\lg G_{2 a}$ & $+(0.859)$ & + & $201-36.4(45)^{c}$ & $\begin{array}{l}205-36.8 \\
(63 \& 59.2)^{c}\end{array}$ & EXP/ENP & Not diluted & $\geq 1: 50^{d}$ \\
\hline $2 \mathrm{E} 5$ & 3 & $\lg G_{2 a}$ & $+(0.732)$ & + & $48.3-36.4(45)^{c}$ & $\begin{array}{l}205-36.8 \\
(63 \& 59.2)^{c}\end{array}$ & EXP/ENP & $\begin{array}{l}\text { Not diluted } \\
\text { (negative for } E \text {. hellem) }\end{array}$ & $\geq 1: 25^{\mathrm{d}}$ \\
\hline $3 \mathrm{~A} 5$ & 2 & $\lg G_{3}$ & $+(1.130)$ & - & 16 & - & CTPC & - & - \\
\hline $3 C 9$ & 2 & $\lg G_{3}$ & $+(1.523)$ & - & $40 \& 16$ & - & CTPC & - & - \\
\hline 1D7 & 2 & $\lg M$ & $+(0.756)$ & - & $40 \& 16$ & - & CTPC & - & - \\
\hline
\end{tabular}




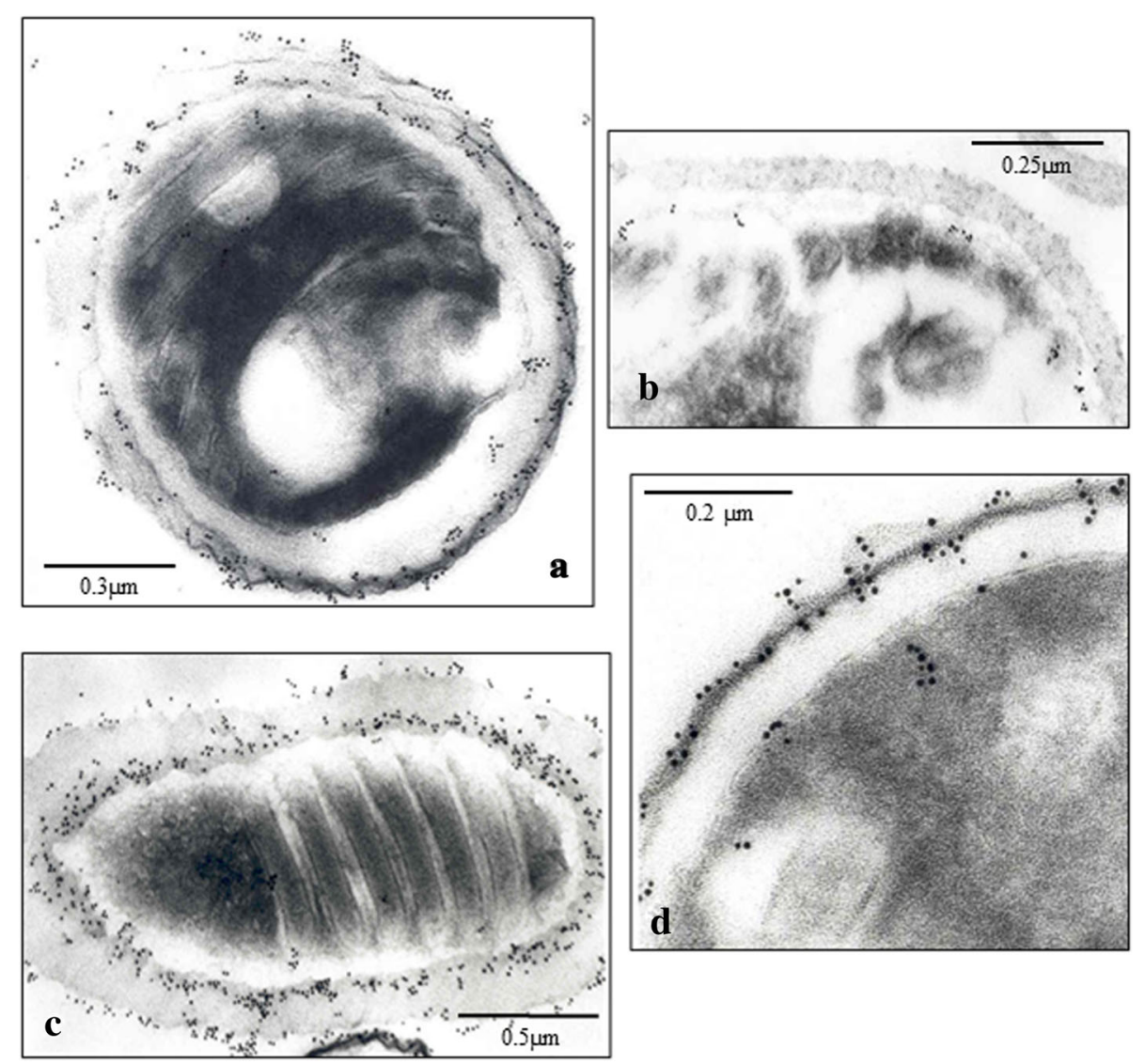

Fig. 2 Immunogold electron micrographs of Encephalitozoon intestinalis spores after incubation with MAbs. Undiluted supernatant were used: 2C2 (a), 3C9 (b), 2E5 (c) and 4C4 (d). Scale-bars: a, $0.3 \mu \mathrm{m} ; \mathbf{b}, 0.25 \mu \mathrm{m} ; \mathbf{c}, 0.5 \mu \mathrm{m} ; \mathbf{d}, 0.2 \mu \mathrm{m}$

MAb 3C9). However, the four IFAT-positive MAbs $(4 \mathrm{C} 4,2 \mathrm{C} 2,2 \mathrm{E} 5$ and $2 \mathrm{H} 2)$ reacted against epitopes of the wall of the spore (exospore and endospore) (Fig. 2a-d).

Immunorecognized stage of development of $E$. intestinalis in cell culture

The cellular cultures infected with E. intestinalis spores were studied in order to describe the reactivity of the MAbs to the different stages of development of the spore. The seven MAbs showed recognition of developed parasitophorous vacuoles from the first hours of infection to $72 \mathrm{~h}$. The developmental stages were also observed (Fig. 3). MAbs (4C4, 2C2, 2E5 and 2H2) and the polyclonal serum recognized perfectly the infectant mature spores.

MAbs (3A5, 1D7 and 3C9) only presented activity against the parasitophorous vacuoles detecting the stages of development that are inside. These same MAbs did not recognize or detect the infectant mature spores. Finally, none of the seven MAbs, recognized the extrude filaments.

\section{Diagnosis of microsporidian spores in human fecal samples by IFAT and staining methods}

The results obtained using IFAT with the MAbs agreed with those of the staining techniques. Encephalitozoon intestinalis-positive samples showed a positive reaction with the four MAbs that recognized the exospore while negative results were obtained when $E$. bieneusi-positive samples were tested (Table 2, Fig. 4a, b). However, the number of spores stained with CF was lower compared with the total number of spores observed in the other stains and by IFAT (Fig. 4c, d).

\section{Mass spectrometry and proteins}

The four IFAT-positive MAbs (4C4, 2C2, 2H2 and 2E5) displayed the same profiles of immunoreactivity (iBlot ${ }^{\mathrm{TM}}$ Dry Blotting System) using soluble antigen of E. cuniculi (Fig. 5). The immunoreactivity profile allowed the clear identification of 5 fractions (9-13, Fig. 5) in a range between 37 to $50 \mathrm{KDa}$, with two well-defined bands, 37 and $45 \mathrm{KDa}$, in the fractions 13 and 11, respectively. Spectra of microsporidian protein extracts revealed the presence of different proteins in the 5 fractions studied (Table 3). It is important to highlight the detection of 

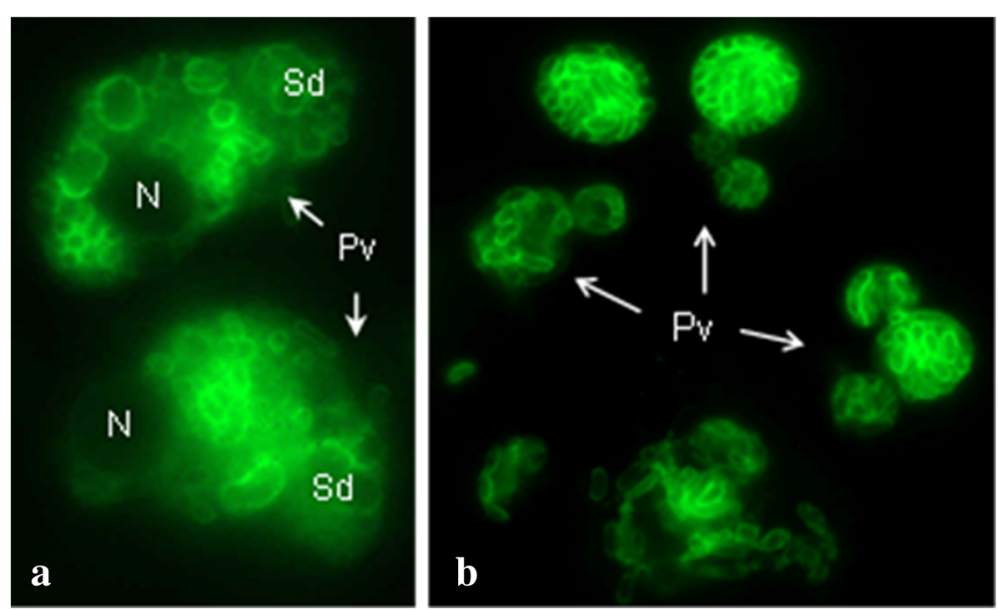

Fig. 3 Immunorecognized in culture cell (Vero-E6) of E. intestinalis after incubation with MAb 2E5 (undiluted supernatant). a 24 hpi. b 72 hpi. Abbreviations: N, nucleus; Pv, parasitophorous vacuole; Sd, stages of development; hpi, hours post-infection

the Spore Wall Protein 1 (SWP1) only in the fractions 11 and 13, with a mass weight of 45,844 Da (Table 3). Moreover, in all fractions, other peptides corresponding to cytosolic proteins or cytoplasmic contents were identified.

\section{Discussion}

The present study reports the production, characterization and reactivity of seven MAbs directed against E. intestinalis, the second most common microsporidia infecting immunodeficient patients. Microsporidian infections are difficult to diagnose because these parasites are difficult to distinguish from bacteria and small yeasts, mainly in stool samples. Staining methods such as Modified Trichrome (MT), Gram-Chromotrope (GC) and Calcofluor (CF), have been used in previous studies to detect microsporidia in clinical samples, but have shown some difficulties in interpretation [6, 17, 21, 37].

An immunofluorescence assay with monoclonal antibodies is a highly sensitive and specific technique, with lower background noise and without cross-reactivity with other bacteria, fungi or parasites, compared to polyclonal antibodies. Immunofluorescence assays using polyclonal serum produced in rabbits against E. hellem, E. cuniculi, E. intestinalis and E. bieneusi have shown the existence of cross-reactions among the different species of Encephalitozoon and with E. bieneusi, indicating the presence of common antigens between genus and species [38]. In addition, cross-reactions with bacteria and fungi have been observed, although morphological characteristics and size can help to distinguish them from the microsporidian spores [28, 39-44].

Seven MAbs were initially selected according to their optical density (OD). Four (4C4, 2C2, $2 \mathrm{E} 5$ and $2 \mathrm{H} 2$ ) were isotype $\mathrm{IgG}_{2 \mathrm{a}}$; two (3A5 and $3 \mathrm{C}$ ) ) isotype $\mathrm{IgG}_{3}$, and one MAb, 1D7, IgM isotype. The study by IFAT showed different behavior depending on the MAbs studied. The MAbs 4C4, 2C2, 2E5 and 2H2 showed reactivity against the exospore, whereas the MAbs 3A5, 1D7 and 3C9 were characterized by the absence of reactivity.

The study of cross-reactions by IFAT with other microsporidian species showed a significant recognition of the spores of $E$. cuniculi with respect to the spores of E. hellem for MAbs 4C4, 2C2, 2E5 and 2H2, when the undiluted supernatants were used. These results demonstrate the presence or absence of certain epitopes in

Table 2 Results of three staining techniques and IFAT for identification of microsporidian spores in fecal specimens from AIDS patients

\begin{tabular}{|c|c|c|c|c|c|c|c|c|}
\hline \multicolumn{2}{|c|}{ Fecal positive samples $(n=26)$} & \multicolumn{3}{|c|}{ Staining methods } & \multicolumn{4}{|c|}{ IFAT } \\
\hline \multirow[t]{2}{*}{ Species n (\%) } & \multirow{2}{*}{$\begin{array}{l}\text { Spore } \\
\text { quantity }\end{array}$} & \multirow[t]{2}{*}{ CF } & \multirow[t]{2}{*}{ MT } & \multirow[t]{2}{*}{ GC } & \multicolumn{4}{|c|}{ MAb } \\
\hline & & & & & $4 C 4$ & $2 \mathrm{C} 2$ & $2 \mathrm{E} 5$ & $2 \mathrm{H} 2$ \\
\hline \multirow[t]{3}{*}{ E. intestinalis $18(70 \%)$} & VN: 6 & $6^{a}$ & 6 & 6 & 6 & 6 & 6 & 6 \\
\hline & $\mathrm{N}: 1$ & $1^{a}$ & 1 & 1 & 1 & 1 & 1 & 1 \\
\hline & F: 11 & $11^{a}$ & 11 & 11 & 11 & 11 & 11 & 11 \\
\hline E. bieneusi 8 (30\%) & $\mathrm{F}: 8$ & $8^{a}$ & 8 & 8 & - & - & - & - \\
\hline
\end{tabular}

${ }^{\mathrm{a}}$ Fewer spores per field

Abbreviations: VN very numerous, N numerous, F few, CF Calcofluor, MT Modified Trichrome, GC Gram-chromotrope 

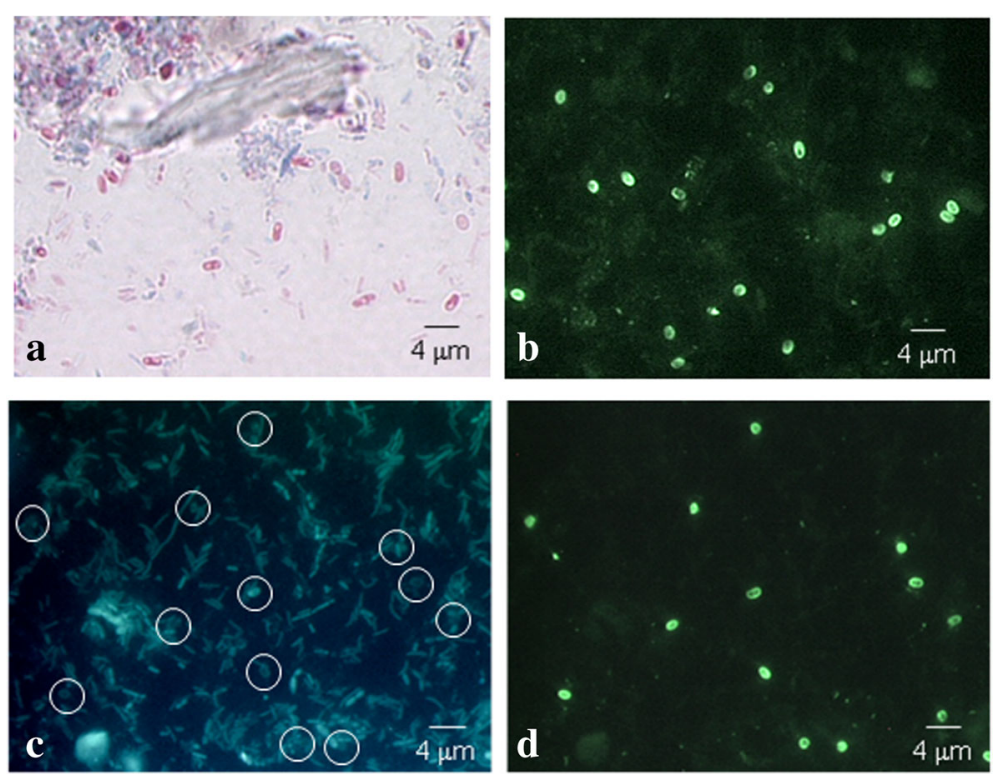

Fig. 4 Formalin-fixed fecal samples from patients with microsporidia. a Fecal smear stained by the Modified Trichrome technique. $\mathbf{b}$ Encephalitozoon intestinalis spores detected by IFAT with the MAb 2E5. c and $\mathbf{d}$ are the same field: c Fecal smear stained by the Calcofluor technique. $\mathbf{d}$ Spores detected by IFAT with MAb 2C2. Scale-bars: $4 \mu \mathrm{m}$

each species and the possible presence of common genus epitopes $[45,46]$. It is important to note that $\mathrm{MAb} 2 \mathrm{E} 5$ could be useful in the specific diagnosis of $E$. intestinalis. In the case of $E$. bieneusi, no cross-reactions were detected.
The results obtained by Western blot with soluble fractions of E. intestinalis confirmed the results by IFAT. MAbs $4 \mathrm{C} 4,2 \mathrm{C} 2$ and $2 \mathrm{H} 2$ recognized protein fractions from 201 to $36.4 \mathrm{KDa}$, as previously described by other authors [45-53], as well as an antigenic fraction of 45
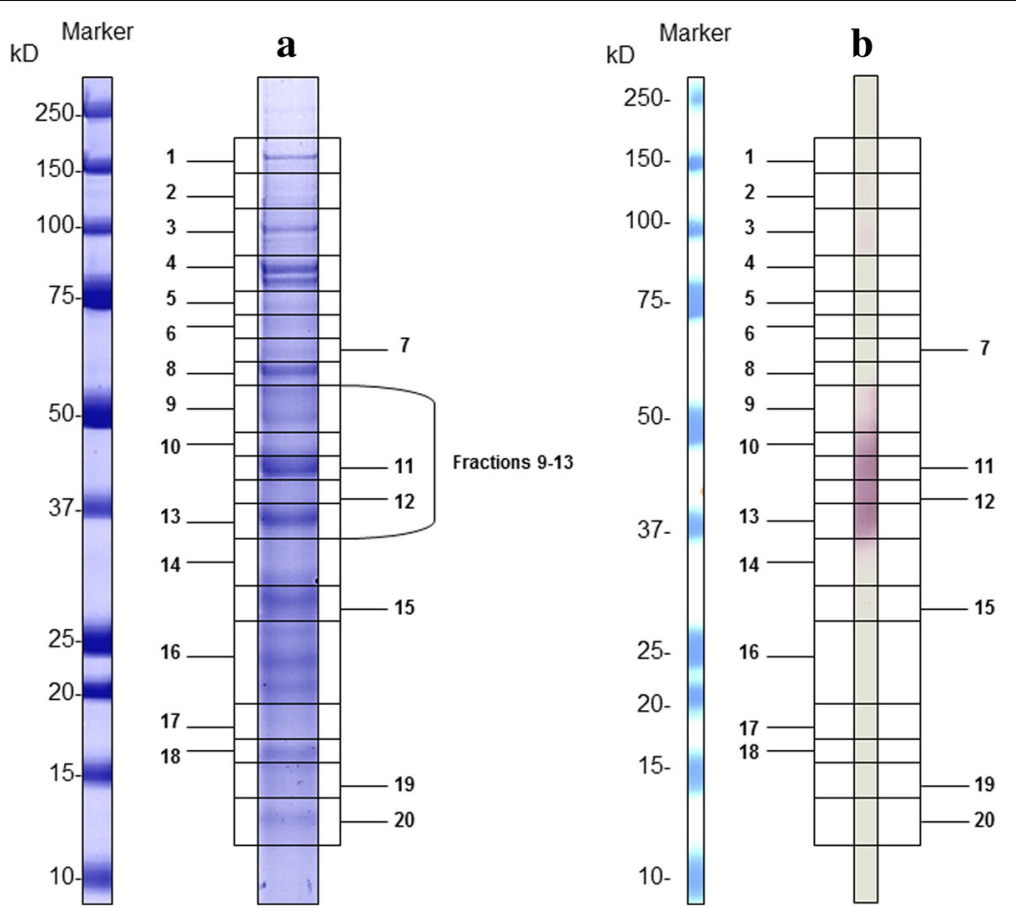

Fig. 5 Soluble antigen profiles of E. cuniculi. a Soluble antigen in NuPage ${ }^{\circledast}$ gel stained with Coomasie Blue. $\mathbf{b}$ Immunoreactivity profile of MAb 2C2 (dilution 1:20, iBlot $^{\text {TM }}$ Dry Blotting System, Invitrogen ${ }^{\mathrm{TM}}$ ) 
Table 3 Proteins identified in the five fractions studied by Q-TOF MS/MS

\begin{tabular}{|c|c|c|c|}
\hline No. of fractions & Accession number & Description & Protein $\mathrm{mW}(\mathrm{Da})$ \\
\hline \multirow[t]{5}{*}{9} & Q8SWI4_ENCCU & Putative protein ECU01 1270 & 22,492 \\
\hline & Q8SQL1_ENCCU & Protein disulfide isomerase & 50,357 \\
\hline & Q8SQZ7_ENCCU & Cytosol aminopeptidase-LEUxPRO & 52,355 \\
\hline & IF4A_ENCCU & ATP dependent RNA helicase & 48,460 \\
\hline & Q8SU65_ENCCU & Similarity chito-oligosaccharide deacetylase & 28,059 \\
\hline \multirow[t]{4}{*}{10} & ACT_ENCCU & Actin E. cuniculi & 41,966 \\
\hline & Q8SVP6_ENCCU & Putative protein ECU04 1630 & 49,997 \\
\hline & ABC1_ENCCU & Probable $A B C$ transporter ECU01 & 65,515 \\
\hline & Q8SV25_ENCCU & Putative protein ECU07 0530 & 48,113 \\
\hline \multirow[t]{4}{*}{11} & ACT_ENCCU & Actin E. cuniculi & 41,966 \\
\hline & Q8SWL3_ENCCU & Putative protein ECU01 0820 & 40,557 \\
\hline & Q8SVN5_ENCCU & Putative protein ECU05 0110 & 36,091 \\
\hline & SWP1_ENCCU & Spore wall protein 1 & 45,844 \\
\hline \multirow[t]{3}{*}{12} & Q8SQW6_ENCCU & U5 associated snRNP & 36,571 \\
\hline & Q8SVT5_ENCCU & Putative protein ECU04 0990 & 25,815 \\
\hline & Q8SRB0_ENCCU & Guanine nucleotide binding protein beta subunit. & 36,727 \\
\hline \multirow[t]{9}{*}{13} & Q8SUE5_ENCCU & Putative protein ECU10 0880 & 35,379 \\
\hline & Q8SRTO_ENCCU & Polar tube protein PTP2 & 30,056 \\
\hline & ACT_ENCCU & Actin E. cuniculi & 41,966 \\
\hline & Q8SR69_ENCCU & Inorganic pyrophosphatase & 31,851 \\
\hline & Q8SSK6_ENCCU & Aldose reductase & 33,335 \\
\hline & Q8SVN2_ENCCU & Putative protein ECU05 0140 & 51,285 \\
\hline & Q8SSD6_ENCCU & CAAX prenyl protease 1 & 47,329 \\
\hline & SWP1_ENCCU & Spore wall protein 1 & 45,844 \\
\hline & Q8SWI4_ENCCU & Putative protein ECU01 1270 & 22,492 \\
\hline
\end{tabular}

$\mathrm{KDa}$, recognized with significant intensity [53]. MAb 2E5 showed a recognition of more reduced bands within the range 48.3 to $36.4 \mathrm{KDa}$ [51-53], and as in the three previous cases, the band recognized with significant intensity was $45 \mathrm{KDa}$ [53].

Several studies have described and associated different bands characterized by Western blot with possible proteins such us the antigen targets recognized by MAbs $[49,50]$. The four IFAT-positive MAbs (Pattern 1: 4C4, 2C2, 2H2 and Pattern 2: 2E5) all showed a well-defined band at $45 \mathrm{KDa}$. These results could relate to the protein EiSWP1 $(\approx 50 \mathrm{KDa})$ which is localized in the exospores of mature spores [49]. The results obtained with these 4 MAbs in the cellular cultures infected with $E$. intestinalis, showed reactivity to the different stages of development of the spores in the parasitophorous vacuoles. This recognition will be again associated with the protein EiSWP1 located in the transition from the stages of meront to sporont and in the final stages of maturation (mature spores) [49]. These results might justify the minor presence of cross-reactions of the 2E5 antibody with respect to antibodies $4 \mathrm{C} 4,2 \mathrm{C} 2$ and $2 \mathrm{H} 2$ that recognize a large number of common epitopes among the Encephalitozoon species.

The results obtained by mass spectrometry and proteomics confirmed that the main epitope recognized by the IFAT-positive Mabs is SWP1, with a molecular weight $(\mathrm{MW})$ of $45,844 \mathrm{Da}$ (using soluble antigen of $E$. cuniculi). This result supports the results obtained by the MS result, which strongly confirms our MET findings which indicated the precise recognition of the exospore (spore wall) and total absence of reactivity against internal epitopes (cytoplasmic contents or cytosolic proteins). Although the MW obtained by Western blot [29] with these same Mabs against E. cuniculi were slightly different to the two well-defined bands of 63 and 59.2 $\mathrm{KDa}$, these differences could be due mainly to the special and specific conditions of the study by proteomics such as: types and characteristics of gels used, treatment of the soluble antigen, conditions of electrophoresis and the separation of the peptides by LC (monomers, dimers or polymers of a same protein). 
It is important to emphasize the total absence of reactivity of the four antibodies to E. bieneusi spores and, the absence of cross-reactions when the study was performed by IFAT with saturated supernatants against other enteric parasites and enteric bacteria [8, 46, 54]. These results support the use of the MAbs described in fecal samples for the diagnosis and/or confirmation of microsporidiosis produced by Encephalitozoon species.

MAbs 3A5, 1D7 and 3C9, with absence of reactivity in IFAT, exhibited different behavior with respect to the previous four. MAbs 1D7 and 9C9 recognized antigenic fractions of 40 and $16 \mathrm{KDa}$ (Pattern 3) in the soluble antigen of E. intestinalis $[51,53]$ while the antibody $3 \mathrm{~A} 5$ recognized only one band of $16 \mathrm{KDa}$ (Pattern 4). It is important to highlight that they did not react with any antigens of E. hellem and E. cuniculi.

The protein of molecular weight $40 \mathrm{KDa}$ is related with the sporogony, but the epitope recognized by the MAb becomes inaccessible showing a negative reactivity by IFAT [50]. However, the protein of $16 \mathrm{KDa}$ could be compared with a band of $\approx 23 \mathrm{KDa}$ described and associated with the sporogony phase [50]. The presence of several or multiple proteins (bands) recognized by the MAbs studied could be due to the presence of the epitopes present in different antigens or proteins, or in the same protein depending on the chemical treatment for the analysis by Western blot, or the presence of monomers, dimers or polymers of the same protein.

The results obtained by electron microscopy (Immunogold) confirmed the IFAT results obtained. 4C4, 2C2, $2 \mathrm{E} 5$ and $2 \mathrm{H} 2 \mathrm{MAbs}$ recognized the exospore, and the total absence of reactivity by IFAT of MAbs 3A5, 1D7 and 3C9 was due to their union with internal structures of the spore [13, 45, 50-52, 55].

Finally, seven MAbs were tested against infected VeroE6 cells with E. intestinalis at 24, 48 and $72 \mathrm{~h}$ postinfection by IFAT with the aim of elucidating the antigenic distribution of the epitopes and their expression during the developmental stages. Three different patterns of immunoreactivity were established.

Included in the first pattern are the IFAT-positive MAbs (4C4, 2C2, 2E5 and 2H2). All of these recognized mature spores and the intraparasitophorous vacuole stages. These results suggest that the final components of the spore wall begin to be expressed in very immature stages of the parasite. In the second pattern, the antibodies 1D7 and 3C9 recognized exclusively developmental stages. These two MAbs were not able to recognize mature spores, suggesting the possibility that the epitopes are synthesized and expressed in the first phases of the development, the antigens remaining within in the cytoplasmic contents (sporoplasm) as cover antigens, undetectable in the mature stages of the spore by IFAT. This fact correlates with the results obtained in the studies by electron microscopy described above [13, 45, 50-52].

The third pattern of fluorescence was exhibited by MAb 3A5, which presented reactivity during all the developmental stages. The recognized epitopes appeared with a diffuse distribution inside of the parasitophorous vacuoles. Therefore, the recognized antigen would be located within the cytoplasmic contents, appearing not to be associated or related to the structural components of the parasite. Again, this behavior correlated with the results obtained by electron microscopy, confirming that the recognized epitope was located in the cytoplasmic contents, not associated with the wall of the parasite.

In order to establish the usefulness of MAbs in microsporida diagnosis, a comparative analysis using a reference technique (CF) was perfomred. The results obtained by IFAT with MAbs 4C4, 2C2, $2 \mathrm{E} 5$ and $2 \mathrm{H} 2$ appeared to be highly specific. Encephalitozoon intestinalis spores were identified in 18 positive fecal samples corresponding with the results of the staining techniques. The spores were easily distinguished with bright fluorescence by IFAT, while with CF in the same field the number of fluorescent spores was low, weak or absent, due to a possible degeneration of the chitin [17]. This could give rise to the presence of false negatives or the underestimation of the parasitic load. Moreover, sometimes CF could favor some false positive diagnosis due to the similarity in the staining of small yeast cells.

It is well-known that diagnosis of microsporidiosis at the species level is important for the treatment of patients. Molecular techniques present high sensitivity and specificity but may also present several disadvantages, such as being more expensive, timeconsuming, the possible presence of inhibitors in the clinical samples and the need for qualified professionals [9-12]. The application of MAbs (4C4, 2C2, 2E5 and 2H2) in stool samples by IFAT showed a good sensitivity and specificity and allowed us to identify the microsporidian spores faster and easier than with CF, GC and MT, due to bright fluorescence of the spore wall that facilitates the diagnosis even to the untrained eye. These results indicate that E. intestinalis and Encephalitozoon spores can be identified in fresh and fixed stool samples and stored at $4{ }^{\circ} \mathrm{C}$ for several years.

\section{Conclusions}

In summary, the different patterns of fluorescence observed in mature spores and in different stages of development suggest the possible utility of these 7 MAbs in the diagnosis of E. intestinalis and Encephalitozoon spp. in fecal and histological samples from human and 
animal hosts. This is the first report on the characterization and use of MAbs $(4 \mathrm{C} 4,2 \mathrm{C} 2,2 \mathrm{E} 5$ and $2 \mathrm{H} 2$ ) in in vitro cultures that could permit their use in tissue samples or biopsies for the detection of the developmental stages. It can be concluded that the use of these MAbs could help in the study of the expression, distribution and characterization of epitopes, such as the SWP1 recognized by the Mabs $(4 \mathrm{C} 4,2 \mathrm{C} 2,2 \mathrm{E} 5$ and $2 \mathrm{H} 2$ ), and be useful in the search of new therapeutic targets.

\section{Abbreviations}

CF: Calcofluor stain; ELISA: Enzyme-linked immunosorbent assay; GC: QuickHot Gram Chromotrope stain; IFAT: Indirect immunofluorescence antibody test; MAb: Monoclonal antibody; MT: Modified Trichrome stain; OD: Optical density

\section{Acknowledgements}

The authors are indebted to José María Garrido (DVM) for his valuable veterinary assistance health care and to Brian Crilly for his helpful revision of the manuscript. The findings and conclusions in this report are those of the authors and do not necessarily represent the official position of the Centers for Disease Control and Prevention (CDC).

\section{Funding}

The study was financially supported by the Universidad San Pablo CEU, Fundación CajaMadrid and Fundación Banco Santander. Fernando Izquierdo Arias was supported in the CDC (USA) by an overseas fellowship from "Ayudas a la Movilidad Investigadora" CEU-Banco Santander (Spain).

\section{Availability of data and materials}

Not applicable.

\section{Authors' contributions}

Experiments were designed and performed by $\mathrm{Fl}, \mathrm{CA}, \mathrm{SF}, \mathrm{GV}, \mathrm{HM}$ and $\mathrm{RS}$. The data were analyzed by FI, CA, SF, FJB, HM and GV. The manuscript was written and reviewed by $\mathrm{Fl}, \mathrm{CA}, \mathrm{SF}, \mathrm{FJB}, \mathrm{GV}, \mathrm{HM}, \mathrm{CH}$ and $\mathrm{AM}$. All authors read and approved the final manuscript.

\section{Ethics approval and consent to participate}

Human fecal samples: all fecal samples were from patients in Atlanta hospitals and established in the CDC fecal bank at the Division of Parasitic Diseases ("Measure the incidence of and risk factors of diarrhea associated with parasitic infections among people infected with HIV" from January 1 , 1991 to September 30,1994/CDC). Informed consent was obtained from patients, and the guidelines for human experimentation of the U.S. Department of Health and Human Services (HHS) were followed. All samples were analyzed anonymously. The authors confirm that the study was reviewed and approved by an institutional review board (HHS) following the Basic HHS Policy for Protection of Human Research Subjects before the study began. Animals: all of the experimental procedures were carried out in accordance with Spanish legislation (Real Decreto 223/1988) and European Union (Council Directive 86/609/EEC) on the use of experimental animals, use of infectious agents and laboratory safety (Real Decreto 664/1997). The studies and protocols were approved by the Veterinary Commission of the University San Pablo CEU (references no. 09/98 and 01/99).

\section{Consent for publication}

Not applicable.

\section{Competing interests}

The authors declare that they have no competing interests.

\section{Publisher's Note}

Springer Nature remains neutral with regard to jurisdictional claims in published maps and institutional affiliations.

\section{Author details}

'Laboratorio de Parasitología, Universidad San Pablo CEU, Madrid, Spain.

${ }^{2}$ Centers for Disease Control and Prevention, Atlanta, GA, USA. ${ }^{3}$ Universidad Miguel Hernández de Elche, Elche, Spain.

Received: 13 January 2017 Accepted: 29 October 2017

Published online: 09 November 2017

\section{References}

1. Didier ES, Didier PJ, Snowden KF, Shadduck JA. Microsporidiosis in mammals. Microbes Infect. 2000;2:709-20.

2. Didier ES. Microsporidiosis: an emerging and opportunistic infection in humans and animals. Acta Trop. 2005;94:61-76.

3. Ojuromi OT, Izquierdo F, Fenoy S, Fagbenro-Beyioku A, Oyibo W, Akanmu A, et al. Identification and characterization of microsporidia from fecal samples of HIV-positive patients from Lagos, Nigeria. PLoS One. 2012;7:e35239.

4. Sak B, Kváč M, Kučerová Z, Květoňová D, Saková K. Latent microsporidial infection in immunocompetent individuals - a longitudinal study. PLoS Negl Trop Dis. 2011;5:e1162.

5. Weber R, Bryan RT, Schwartz DA, Owen RL. Human microsporidial infections. Clin Microbiol Rev. 1994;7:426-61.

6. Weber R, Bryan RT, Owen RL, Wilcox CM, Gorelkin L, Visvesvara GS, The Enteric Opportunistic Infections Working Group. Improved lightmicroscopical detection of microsporidia spores in stool and duodenal aspirates. N Engl J Med. 1992;326:161-6.

7. Kokoskin E, Gyorkos TW, Camus A, Cedilotte L, Purtill T, Ward B. Modified technique for efficient detection of microsporidia. J Clin Microbiol. 1994;32: 1074-5.

8. Mo L, Drancourt M. Monoclonal antibodies for specific detection of Encephalitozoon cuniculi. Clin Diagn Lab Immunol. 2004;11:1060-3.

9. Boom R, Sol CJ, Salimans MM, Jansen CL, Wertheim-van Dillen PM, van der Noordaa J. Rapid and simple method for purification of nucleic acids. J Clin Microbiol. 1990;28:495-503.

10. Fedorko DP, Nelson NA, Cartwright CP. Identification of microsporidia in stool specimens by using PCR and restriction endonucleases. J Clin Microbiol. 1995;33:1739-41.

11. Katzwinkel-Wladarsch S, Lieb M, Helse W, Löscher T, Rinder H. Direct amplification and species determination of microsporidian DNA from stool specimens. Tropical Med Int Health. 1996;1:373-8.

12. Liguory O, David F, Sarfati C, Schuitema AR, Hartskeerl RA, Derouin F, et al. Diagnosis of infections caused by Enterocytozoon bieneusi and Encephalitozoon intestinalis using polymerase chain reaction in stool specimens. AIDS. 1997;11:723-6.

13. Accoceberry I, Thellier M, Desportes-Livage I, Achbarou A, Biligui S, Danis M, et al. Production of monoclonal antibodies directed against the microsporidium Enterocytozoon bieneusi. J Clin Microbiol. 1999;37:4107-12.

14. Alfa Cisse O, Ouattara A, Thellier M, Accoceberry I, Biligui S, Minta D, et al. Evaluation of an immunofluorescent-antibody test using monoclonal antibodies directed against Enterocytozoon bieneusi and Encephalitozoon intestinalis for diagnosis of intestinal microsporidiosis in Bamako (Mali). J Clin Microbiol. 2002;40:1715-8.

15. Didier ES, Vossbrinck CR, Baker MD, Rogers LB, Bertucci DC, Shadduck JA. Identification and characterization of three Encephalitozoon cuniculi strains. Parasitology. 1995;111:411-21.

16. Enriquez FJ, Taren D, Cruz-López A, Muramoto M, Palting JD, Cruz P. Prevalence of intestinal encephalitozoonosis in Mexico. Clin Infect Dis. 1998; 26:1227-9.

17. Didier ES, Orenstein JM, Aldras A, Bertucci D, Rogers LB, Janney FA. Comparison of three staining methods for detecting microsporidia in fluids. J Clin Microbiol. 1995;33:3138-45.

18. Kucerova Z, Moura H, Leitch GJ, Sriram R, Bern C, Kawai V, et al. Purification of Enterocytozoon bieneusi spores from stool specimens by gradient and cell sorting techniques. J Clin Microbiol. 2004;42:3256-61.

19. Li X, Tate KW, Dunbar LA, Huang B, Atwill ER. Efficiency for recovering Encephalitozoon intestinalis spores from waters by centrifugation and immunofluorescence microscopy. J Eukaryot Microbiol. 2003;50(Suppl): $579-80$

20. Lobo ML, Teles A, da Cunha MB, Henriques J, Lourenço AM, Antunes F, et al. Microsporidia detection in stools from pets and animals from the zoo in Portugal: a preliminary study. J Eukaryot Microbiol. 2003;50(Suppl):581-2. 
21. Matos O, Lobo ML, Gonçalves L, Antunes F. Diagnostic use of 3 techniques for identification of microsporidian spores among AIDS patients in Portugal. Scand J Infect Dis. 2002;34:591-3.

22. Mohindra AR, Lee MW, Visvesvara G, Moura H, Parasuraman R, Leitch GJ, et al. Disseminated microsporidiosis in a renal transplant recipient. Transpl Infect Dis. 2002:4:102-7.

23. Moura H, Sodre FC, Bornay-Llinares FJ, Leitch GJ, Navin T, Wahlquist S, et al. Detection by an immunofluorescence test of Encephalitozoon intestinalis spores in routinely formalin-fixed stool samples stored at room temperature. J Clin Microbiol. 1999;37:2317-22.

24. Sheoran AS, Feng X, Singh I, Chapman-Bonofiglio S, Kitaka S, Hanawalt J, et al. Monoclonal antibodies against Enterocytozoon bieneusi of human origin. Clin Diagn Lab Immunol. 2005;12:1109-13.

25. Sheoran AS, Feng X, Kitaka S, Green L, Pearson C, Didier ES, et al. Purification of Enterocytozoon bieneusi from stools and production of specific antibodies. J Clin Microbiol. 2005:43:387-92.

26. Shrestha AK, Enriquez FJ. Short report: prevalence of fecal Encephalitozoon sp. spores among hospitalized patients in Nepal. Am J Trop Med Hyg. 2001; 65:648-9.

27. Weiss LM, Vossbrinck CR. Microsporidiosis: molecular and diagnostic aspects. Adv Parasitol. 1998:40:351-95.

28. Visvesvara GS, da Silva AJ, Croppo GP, Pieniazek NJ, Leitch GJ, Ferguson D, et al. In vitro culture and serologic and molecular identification of Septata intestinalis isolated from urine of a patient with AIDS. J Clin Microbiol. 1995; 33:930-6.

29. del Aguila C, Moura H, Fenoy S, Navajas R, Lopez-Velez R, Li L, et al. In vitro culture, ultrastructure, antigenic, and molecular characterization of Encephalitozoon cuniculi isolated from urine and sputum samples from a Spanish patient with AIDS. J Clin Microbiol. 2001;39:1105-8.

30. Scaglia M, Gatti S, Sacchi L, Corona S, Chichino G, Bernuzzi AM, et al. Asymptomatic respiratory tract microsporidiosis due to Encephalitozoon hellem in three patients with AIDS. Clin Infect Dis. 1998:26:174-6.

31. Visvesvara GS, Leitch GJ, Moura H, Wallace S, Weber R, Bryan RT. Culture, electron microscopy, and immunoblot studies on a microsporidian parasite isolated from the urine of a patient with AIDS. J Protozool. 1991;38:105S-11S.

32. del Aguila C, Rueda C, De la Camara C, Fenoy S. Seroprevalence of antiEncephalitozoon antibodies in Spanish immunocompetent subjects. J Eukaryot Microbiol. 2001;(Suppl):75S-8S.

33. Köhler G, Milstein C. Continuous cultures of fused cells secreting antibody of predefined specificity. Nature. 1975;256:495-7.

34. Pomport-Castillon C, Gasc C, Romestand B. Development, characterization and future prospects of monoclonal antibodies against spores of Glugea atherinae (protozoa-microsporidia-fish parasites). J Eukaryot Microbiol. 1997; 44:643-8.

35. Moura H, Schwartz DA, Bornay-Llinares F, Sodré FC, Wallace S, Visvesvara GS. A new and improved "quick-hot gram-chromotrope" technique that differentially stains microsporidian spores in clinical samples, including paraffin-embedded tissue sections. Arch Pathol Lab Med. 1997;121:888-93.

36. Moura H, Terilli RR, Woolfitt AR, Gallegos-Candela M, McWilliams LG, Solano Ml, et al. Studies on botulinum neurotoxins type /C1 and mosaic/DC using Endopep-MS and proteomics. FEMS Immunol Med Microbiol. 2011;61:288-300,

37. Matos O, Lobo ML, Antunes F. Methodology of the diagnosis of microsporidiosis in urine and pulmonary specimens from AIDS patients. J Eukaryot Microbiol. 2001;(Suppl):69S-70S.

38. van Gool T, Vetter JC, Weinmayr B, Van Dam A, Derouin F, Dankert J. High seroprevalence of Encephalitozoon species in immunocompetent subjects. J Infect Dis. 1997;175:1020-4.

39. Aldras AM, Orenstein JM, Kotler DP, Shadduck JA, Didier ES. Detection of microsporidia by indirect immunofluorescence antibody test using polyclonal and monoclonal antibodies. J Clin Microbiol. 1994;32:608-12.

40. Niederkorn JY, Shadduck JA, Weidner E. Antigenic cross-reactivity among different microsporidan spores as determined by immunofluorescence. J Parasitol. 1980;66:675-7.

41. Ombrouck C, Romestand B, da Costa JM, Desportes-Livage I, Datry A, Coste $F$, et al. Use of cross-reactive antigens of the microsporidian Glugea atherinae for the possible detection of Enterocytozoon bieneusi by western blot. Am J Trop Med Hyg. 1995;52:89-93.

42. Visvesvara GS, Leitch GJ, da Silva AJ, Croppo GP, Moura H, Wallace S, et al. Polyclonal and monoclonal antibody and PCR-amplified small-subunit rRNA identification of a microsporidian, Encephalitozoon hellem, isolated from an AIDS patient with disseminated infection. J Clin Microbiol. 1994;32:2760-8.
43. Weiss LM, Cali A, Levee E, LaPlace D, Tanowitz H, Simon D, et al. Diagnosis of Encephalitozoon cuniculi infection by western blot and the use of crossreactive antigens for the possible detection of microsporidiosis in humans. Am J Trop Med Hyg. 1992;47:456-62.

44. Zierdt $\mathrm{CH}$, Gill VJ, Zierdt WS. Detection of microsporidian spores in clinical samples by indirect fluorescent-antibody assay using whole-cell antisera to Encephalitozoon cuniculi and Encephalitozoon hellem. J Clin Microbiol. 1993; 31:3071-4.

45. Beckers PJ, Derks GJ, Gool T, Rietveld FJ, Sauerwein RW. Encephalocytozoon intestinalis-specific monoclonal antibodies for laboratory diagnosis of microsporidiosis. J Clin Microbiol. 1996:34:282-5.

46. Enriquez FJ, Ditrich O, Palting JD, Smith K. Simple diagnosis of Encephalitozoon sp. microsporidial infections by using a panspecific antiexospore monoclonal antibody. J Clin Microbiol. 1997;35:724-9.

47. Achbarou A, Thellier M, Accoceberry I, Prigneau O, Bouladoux N, Datry A, et al. Production of immunological probes raised against Enterocytozoon bieneusi and Encephalitozoon intestinalis, two microsporidian species causing intestinal infections in man. J Eukaryot Microbiol. 1999;46:32S-3S.

48. Bouladoux N, Biligui S, Desportes-Livage I. A new monoclonal antibody enzyme-linked immunosorbent assay to measure in vitro multiplication of the microsporidium Encephalitozoon intestinalis. J Microbiol Methods. 2003; 53:377-85.

49. Delbac F, Duffieux F, David D, Metenier G, Vivares CP. Immunocytochemical identification of spore proteins in two microsporidia, with emphasis on extrusion apparatus. J Eukaryot Microbiol. 1998;45:224-31.

50. Hayman JR, Hayes SF, Amon J, Nash TE. Developmental expression of two spore wall proteins during maturation of the microsporidian Encephalitozoon intestinalis. Infect Immun. 2001;69:7057-66.

51. Luján HD, Conrad JT, Clark CG, Touz MC, Delbac F, Vivares CP, et al. Detection of microsporidia spore-specific antigens by monoclonal antibodies. Hybridoma. 1998;17:237-43.

52. Prigneau O, Achbarou A, Bouladoux N, Mazier D, Desportes-Livage I. Identification of proteins in Encephalitozoon intestinalis, a microsporidian pathogen of immunocompromised humans: an immunoblotting and immunocytochemical study. J Eukaryot Microbiol. 2000;47:48-56.

53. Thellier M, Biligui S, Desportes-Livage I, Accoceberry I, Datry A. Monoclonal antibody enabling the diagnosis of Encephalitozoon intestinalis in fecal specimens: importance of the mode of selection of hybridomas. J Eukaryot Microbiol. 2001;(Suppl):71S-2S.

54. Mo L, Drancourt M. Antigenic diversity of Encephalitozoon hellem demonstrated by subspecies-specific monoclonal antibodies. J Eukaryot Microbiol. 2002:49:249-54.

55. Sak B, Saková K, Ditrich O. Effects of a novel anti-exospore monoclonal antibody on microsporidial development in vitro. Parasitol Res. 2004:92:74-80.

\section{Submit your next manuscript to BioMed Central and we will help you at every step:}

- We accept pre-submission inquiries

- Our selector tool helps you to find the most relevant journal

- We provide round the clock customer support

- Convenient online submission

- Thorough peer review

- Inclusion in PubMed and all major indexing services

- Maximum visibility for your research

Submit your manuscript at www.biomedcentral.com/submit
OBioMed Central 